\title{
Oral Lesion Description: A Mini Review
}

\author{
Hamed Mortazavi' ${ }^{1}$, Maryam Baharvand ${ }^{1}$, Kazem Dalaie ${ }^{2}$, Mahdi Faraji ${ }^{3}$, Hamidreza Khalighi ${ }^{1}$, Mohammad Behnaz ${ }^{2 *}$
}

${ }^{1}$ Department of Oral Medicine, School of Dentistry, Shahid Beheshti University of Medical Sciences, Tehran, Iran ${ }^{2}$ Department of Orthodontics, School of Dentistry, Shahid Beheshti University of Medical Sciences, Tehran, Iran 3Dentist, Private Practice, Tehran, Iran

Corresponding Author: Mohammad Behnaz, M.D., Assistant Professor, Department of Orthodontics, School of Dentistry, Shahid Beheshti University of Medical Sciences, Tehran, Iran. Tel: +98-912327802, Email: behnaz1357@yahoo.com

Received May 21, 2019; Accepted July 19, 2019; Online Published September 28, 2019

\begin{abstract}
Introduction: Lesion description has a key role in correct diagnosis and timely treatment. The aim of this study was to review of morphological descriptive terms, which are used in oral lesion description.

Methods: An electronic search of the literature was conducted in various database including: Google Scholar, PubMed, PubMed Central, Science Direct, and Scopus databases, for relevant articles using the following keywords: "oral lesion", "terminology", "semiology", "glossary", "morphology", "primary lesion", "basic lesion", "dermatology", "oral medicine", and "stomatology". About 60 articles were found; out of which, 45 were relevant to our topic of interest. Finally, we included 22 articles that were closely related to the topic of interest. In addition, 4 text books were also used in this study.

Results: After data collection, the following 20 descriptive morphological terms were found. These terms divided into two groups as primary and secondary lesions: (1) Primary lesion: macule, patch, papule, plaque, nodule, tumor, weal (or hive), vesicle, bullae, pustule, abscess, cyst, purpura (petechia \& ecchymosis), and hematoma. (2) Secondary lesion: erosion, ulcer, sinus, fistula, and scar.

Conclusions: The correct and updated descriptive terminology should be considered by dentists in oral examination.

Keywords: Oral, Plaque, Vesicle, Cyst, Patch

Citation: Mortazavi H, Baharvand M, Dalaie K, Faraji M, Khalighi H, Behnaz M. Oral lesion description: a mini review. Int J Med Rev. 2019;6(3):8187. doi:10.29252/ijmr-060303.
\end{abstract}

\section{Introduction}

Oral mucosal lesions may occasionally diagnosed correctly, based on a brief history and clinical examination. ${ }^{1}$ therefore, an accurate description is essential for diagnosis and management of oral lesions. As regards, continuous observation and monitoring of the lesion is required, an acceptable description would be critical for comparison purposes. When biopsy sample is taken, the pathologist needs an accompanying lesion description to reach a definitive diagnosis. Since, questions about the management of lesion may arise, documentation of the description is necessary and should be included in patient records. ${ }^{2}$ Lack of detailed description of oral lesions, can lead to difficulties in prioritizing the oral medicine appointments. ${ }^{3,4} \mathrm{~A}$ thorough oral lesion description must include the following nine items: size (length, width, and height), number (single, multiple), outline (regular, irregular), surface (smooth, granular, verrucous, papillomatous, pebbly, cobblestone), base (pedunculated, sessile, nodular, domeshaped), site (mucosal, intra-bony, dental), color (red, pink, white, red-white combined, blue, purple, gray, yellow, black, or brown according to their prevalence in oral mucosa), consistency (soft, hard, cheesy, firm, rubbery, and fluctuant), origin (acquired, non-acquired), and morphology or clinical appearance (primary lesions, secondary lesions).,5-7 The morphology component is the most challenging aspect of lesion description, which is the main purpose of this review. Study by Zimmermann and colleagues demonstrated that, when lesions have been described based on a guideline and standard definitions in medicine referrals, information quality was higher compared to cases based on a free. ${ }^{3}$ The description and diagnosis of oral lesions, require a basic knowledge about dermatology since, many disorders of the oral mucosa also affect the skin. ${ }^{1,8}$ There are two terms in dermatology glossary for lesion description namely, primary lesions and secondary lesions. The term "primary" is used to describe a lesion as it first appears, for example a macule. A "secondary" lesion results from an alteration of primary lesion either in the natural course of disease or as the result of manipulation or treatment, for example, a scar. ${ }^{9}$ Only a few publications have discussed the importance of morphological examination of descriptive terms in the literature. ${ }^{8}$ Therefore, the purposed of this study was to review the morphological descriptive terms used for oral lesion description.

\section{Methods}

An electronic search of the literature was conducted in

Copyright $\odot 2019$ The Author(s). This is an open-access article distributed under the terms of the Creative Commons Attribution License (http:// creativecommons.org/licenses/by/4.0), which permits unrestricted use, distribution, and reproduction in any medium, provided the original work is properly cited. 
various database including: Google Scholar, PubMed, PubMed Central, Science Direct, and Scopus databases for relevant articles using the following keywords: "oral lesion", "terminology", "semiology", "glossary", "morphology", "primary lesion”, "basic lesion”, “dermatology”, “oral medicine”, and "stomatology". About 60 articles were found; out of which, 45 were relevant to our topic of interest. Twenty-three articles were excluded from the review process for the following reasons: Languages other than English, unavailable full texts and repetitive subjects. Finally, we included 22 articles that were closely related to our topic of interest. In addition, four text-books were also used in this study.

\section{Results}

After data collection, the following 20 descriptive morphological terms were found. These terms were divided into two groups as primary and secondary lesions as follows: (1) Primary lesions: macule, patch, papule, plaque, nodule, tumor, weal (or hive), vesicle, bulla, pustule, abscess, cyst, purpura (petechia and ecchymosis), and hematoma. (2) Secondary lesions: erosion, ulcer, sinus, fistula, and scar.

\section{Primary Lesions}

Macule: It is characterized as a circumscribed, flat area of discoloration in the skin or mucosa that is less than $10 \mathrm{~mm}$ in diameter (Figure 1). ${ }^{7,10}$ According to another definition, it should be smaller than $5 \mathrm{~mm}$ in diameter. ${ }^{3,11}$ However, Bricker described that, macules occur in the same plane of the skin/ mucosa and may be of any size. ${ }^{9}$ This term can be used for amalgam tattoos, ephelis, freckles, focal argyrosis, etc., ${ }^{9,12}$

Patch: It is defined as a flat circumscribed area that is larger than a macule $(>5 \mathrm{~mm}$ or $>10 \mathrm{~mm}$ according to different definitions) (Figure 2). A slight scale may or may not be present. ${ }^{7}$ However, it is not an elevated or palpable lesion.,10,12 Vitiligo, secondary syphilis-related oral mucosal lesions, and severe drug-related pigmentations can be described as a patch. ${ }^{7,9}$

Papule: It is known as a superficial, elevated, solid, circumscribed lesion that is less than $10 \mathrm{~mm} 5 \mathrm{~mm}$ in diameter and may be of any color (Figure 3). ${ }^{1,7,9,11}$ This lesion may be attached to the skin or mucosa by a stalk or firm base. ${ }^{2,12}$ It can arise from either a dermal proliferation, an epidermal proliferation or a combination of both. ${ }^{10}$ Wart, squamous papilloma, parulis and Fordyce granules may present as a

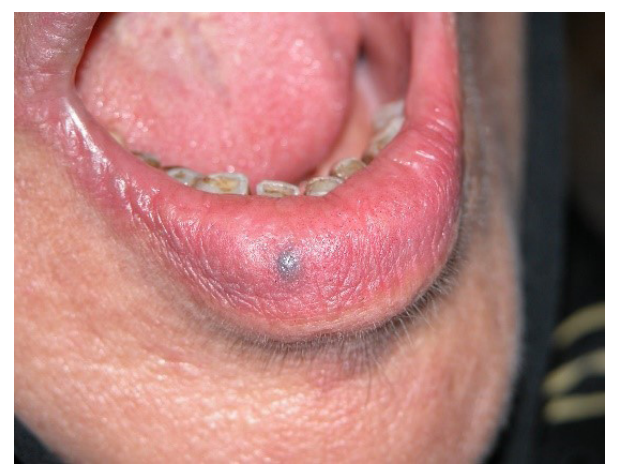

Figure 1. A Circumscribed Macule on the Lower Lip. single or multiple papules in the oral cavity.9,12

Plaque: It is characterized as a superficial, slightly raised, solid, circumscribed lesion greater than $5 \mathrm{~mm}$ or $10 \mathrm{~mm}$ in diameter, which has a broad flat top like a plateau, and a "pasted on" appearance (Figure 4). 2,7,11 Papules can coalesce to form plaque. ${ }^{13}$ Although, essentially superficial, plaques may extend deeper into the dermis than the papule. ${ }^{9}$ However, they are likely to be primarily epidermal in nature. ${ }^{10}$ In the oral cavity, for example, lichen planus, leukoplakia, or melanoma may initially appear as a plaque. ${ }^{12}$

Nodule: It is described as a solid lesion deep in the dermis or mucosa; the epidermis is mobile over it (Figure 5). ${ }^{1}$ There is no specific size for a nodule; however, nodules have been

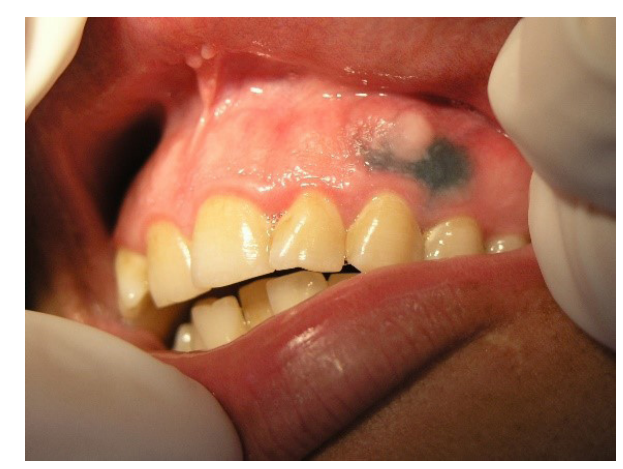

Figure 2. Malignant Melanoma as a Non-homogenous and Asymmetrical Brown-Black Patch on the Keratinized Gingiva.

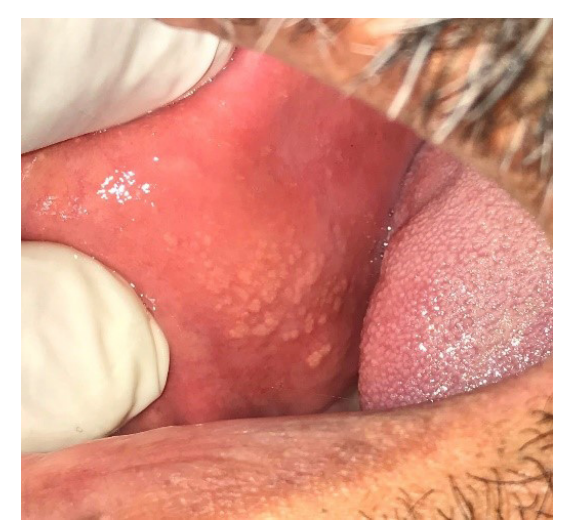

Figure 3. Fordyce Granules as Yellow Papules on the Buccal Mucosa.

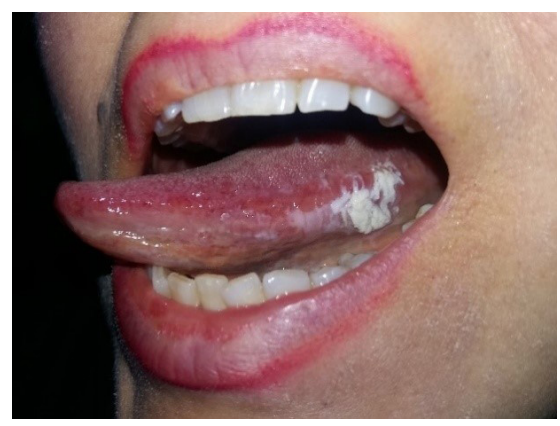

Figure 4. Leukoplakia as a Non-homogenous White Plaque on the Lateral Border of the Tongue. 


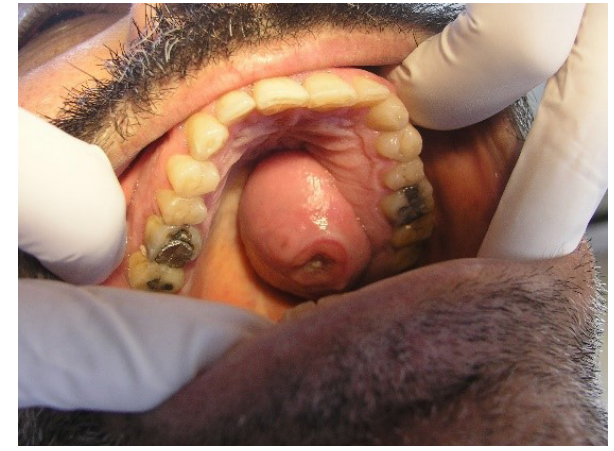

Figure 5. Mucoepidermoid Carcinoma as a Huge Tumor on the Posterior Portion of the Palate.

mentioned to be less than $10 \mathrm{~mm}$ in diameter. ${ }^{7,9,11}$ In two papers, nodules were defined to be greater than $5 \mathrm{~mm}$ and less than $20 \mathrm{~mm}$ in diameter. ${ }^{2,3}$ Clinically, nodules may be above, level with, or below the skin/mucosa and can be detected by palpation. ${ }^{7,12}$ Benign mesenchymal tumors such as lipoma and neuroma can be present as a nodule in the oral mucosa. ${ }^{12}$

Tumor: It is characterized as a solid lesion greater than $10 \mathrm{~mm}$ in diameter (or $20 \mathrm{~mm}$ in diameter), that has the dimension of depth (Figure 6), ${ }^{2,7,9}$ It is also known as a mass with any size. ${ }^{7}$ Tumors may be above, level with, or below the skin/mucosa. ${ }^{7}$ It has been pointed out that, "tumor" is a general medical term for a large nodule and does not imply a malignancy. Unfortunately, the word has come to be equal with cancer, making the term less accurate. ${ }^{10}$ Similar to nodule, benign mesenchymal tumors can be clinically described as a tumor in the oral cavity. ${ }^{12}$

Weal/Hive: It is defined as a transient, circumscribed, edematous smooth-surface papule or plaque resulting from acute extravasations of serum into the upper dermis with a variable diameter. ${ }^{7,910,12,13}$ It may manifest with an erythematous border and pale center and/or a narrow peripheral zone of pallor or vasoconstriction; it is often very itchy. ${ }^{7}$ Allergic reactions and vesiculobullous diseases of the oral mucosa may have such clinical appearance. ${ }^{12}$

Vesicle: It is known as a superficial, raised, circumscribed, blister-form lesion less than $5 \mathrm{~mm}$ or $10 \mathrm{~mm}$ in diameter and is fluid-filled (Figure 7). The fluid may be clear, serous, hemorrhagic or purulent., ${ }^{2,13}$ Vesicles are common results of allergic reactions such as contact allergy to latex or viral infections such as herpes simplex, herpes zoster or chickenpox. ${ }^{12}$

Bulla: It is described as a fluid-filled, superficial, raised, circumscribed, blister-form lesion greater than $5 \mathrm{~mm}$ or 10 $\mathrm{mm}$ in diameter (Figure 8). The fluid can be clear, serous, hemorrhagic or purulent. ${ }^{2,7,13}$ On the skin, bulla is commonly associated with burns, frictional trauma, and allergic contact dermatitis. Intra-oral lesions can be seen in pemphigus vulgaris, pemphigoid, and Stevens-Johnson syndrome. ${ }^{12}$

Pustule: It is described as a purulent (pus-filled) vesicle. Pustules are usually creamy white in color but may be yellow or green. ${ }^{7,9}$ Although, the presence of pus usually suggests an infection, there are many sterile pustules., ${ }^{713}$ These lesions are usually smaller than $10 \mathrm{~mm}$ but may be seen in any size. ${ }^{12}$ In the oral cavity, a pustule presents as a pointing abscess or

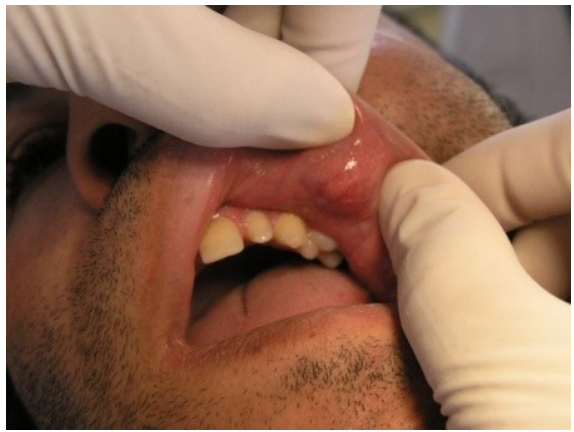

Figure 6. Pleomorphic Adenoma as a Nodule in the Upper Lip.

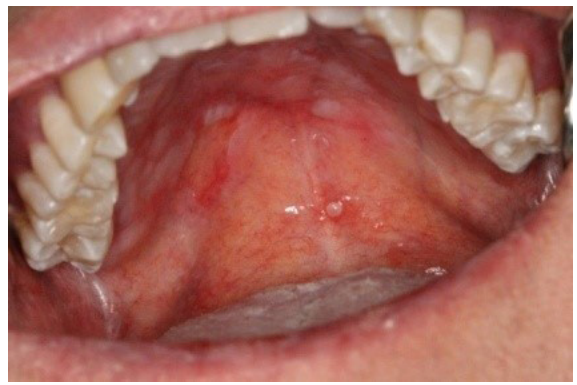

Figure 7. An Intact Vesicle on the Soft Palate Due to an Allergic Reaction.

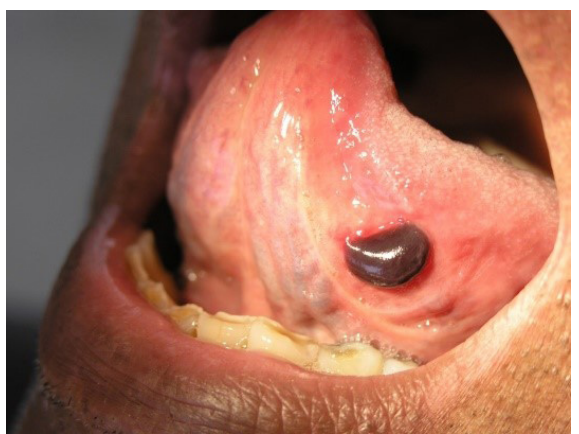

Figure 8. Hemorrhagic Bullae on the Lateral Border of the Tongue Due to Cicatricial Pemphigoid

parulis. Herpes zoster also produces pustules that eventually ulcerate and cause intense pain. ${ }^{12}$

Abscess: It is characterized as a localized accumulation of pus in the skin/mucosa or subcutaneous/submucosal tissue and is often red, warm and tender (Figure 9). ${ }^{7}$ In some cases, it may be a much deeper accumulation of pus that is not visible through the surface. ${ }^{9}$

Cyst: It is defined as an elevated, circumscribed area of the skin or mucosa filled with liquid or semisolid fluid and can be pink to blue or yellow to creamy in color (Figure 10). ${ }^{12-14}$ It also may be level with, or below the skin/mucosa, detected by palpation. ${ }^{10}$ Aspiration of a cyst may or may not yield luminal fluid, depending on the nature of the cyst. ${ }^{9,10}$ In the oral cavity, there are many cystic lesions such as lateral periodontal cyst, eruption cyst, dermoid cyst, incisive canal cyst, odontogenic keratocyst, etc. ${ }^{12,14}$

Purpura/petechia/ecchymosis: They refer to bleeding into the skin or mucosa that results in violet or purple 


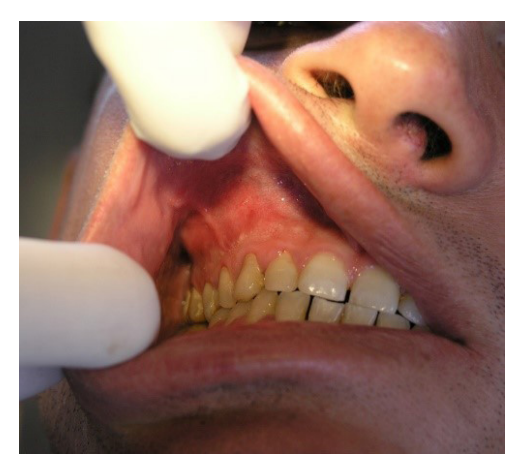

Figure 9. Dental Abscess Due to a Necrotic Tooth.

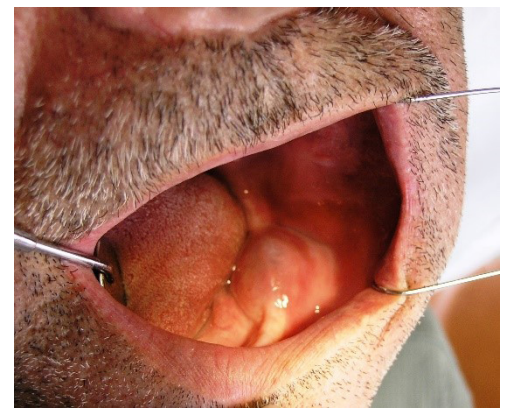

Figure 10. Residual Cyst With Bacco-lingual Expansion and Perforation.

discoloration that varies based on its duration and does not blanch with pressure (Figure 11). Purpura can be divided into two categories of petechia and ecchymosis according to the size of lesion. Petechia is defined as tiny, $1 \mathrm{~mm}$ to $2 \mathrm{~mm}$ pinpoint non-blanchable purpuric macules resulting from the rupture of small blood vessels and can be red, purple or brown in color. ${ }^{1,7}$ Ecchymosis is also described as a nonblanching, purpuric macules greater than $3 \mathrm{~mm}$ in diameter due to extravasated blood in the skin or mucosa. Over time, the color may change from blue-black to brown-yellow or green before fading away.

Hematoma: It refers to collection of extravasated blood relatively or completely confined within a space (Figure 12). The blood is usually completely or partially clotted and according to the lesion duration, it may manifest various degrees of organization and color. ${ }^{7}$ Postdental extraction hematoma and hematoma due to local anesthesia are among the most common complications in dentistry. ${ }^{15}$

\section{Secondary Lesions}

Erosion: It is described as a red, shallow, moist, slightly depressed lesion that often results from a broken vesicle or bulla, epithelial breakdown, or trauma (Figure 13). Erosion should not be mistaken for ulcers, which are covered with fibrin and are usually yellow, although erosions may develop into ulcers. ${ }^{1}$ Healing rarely results in scarring because the basal layer of the epithelium remains intact. Pemphigus, lichen planus, and erythema multiform are diseases that produce mucocutaneous erosions. ${ }^{12}$

Ulcer: It refers to loss of continuity of the epithelium. The center of the lesion is initially red and then turns gray-

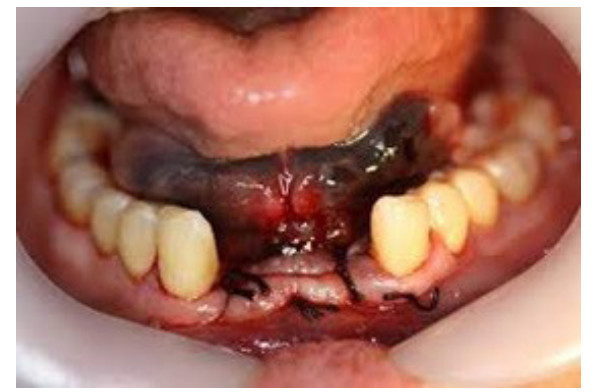

Figure 11. A Large Hematoma on the Floor of the Mouth After Surgical Procedure.

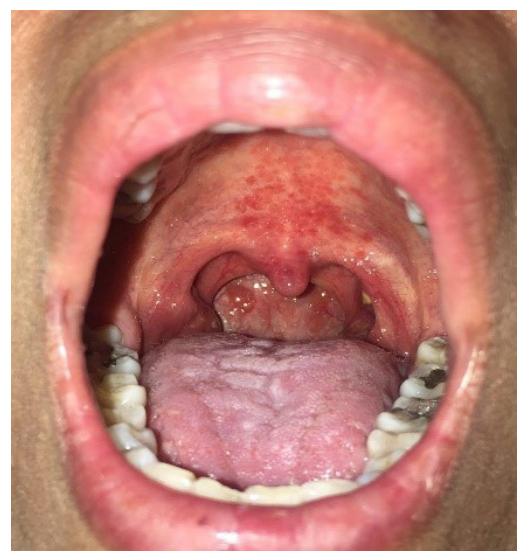

Figure 12. Diffuse Petechia on the Hard and Soft Palate After Viral Infection.

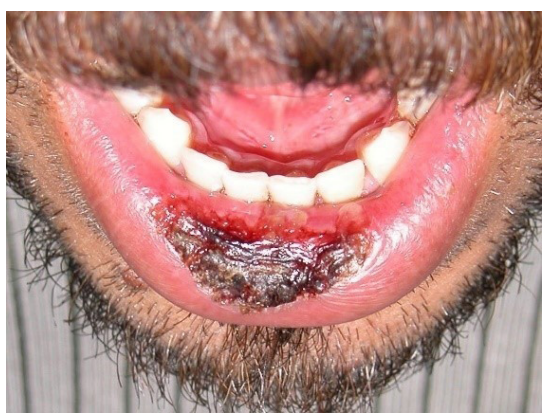

Figure 13. Crusted Ulcer in a Patient With Erythema Multiforme.

white after being covered with fibrin clot (Figure 14). ${ }^{1,9}$ The periphery of the lesion may be erythematous. ${ }^{2}$ Ulcers are further classified according to their depth, border, shape, margin, and the tissue at its base. Ulcers can be superficial or deep. Superficial ulcer shave less than $3 \mathrm{~mm}$ depth while deep ulcers have over $3 \mathrm{~mm}$ depth. ${ }^{13}$ In terms of shape, the ulcers can be divided into symmetric and asymmetric forms according to the degree of regularity of the borders. The margin of the ulcers can be smooth or craterlike when it is above the level of the normal mucosa. ${ }^{16-18}$ Oral ulcers are the most common type of oral lesions such as recurrent aphthous stomatitis, traumatic ulcers, etc. ${ }^{12}$

Fissure: It is known as a sharply defined linear or wedgeshaped tear in the epidermis (skin or mucosa) with abrupt 
walls (Figure 15). ${ }^{7}$ Presence of a fissure can indicate, a condition representing a normal variation or a disease. ${ }^{12}$ Diseases associated with fissures occur, when pathogenic microorganisms (mostly Candida albicans) colonize a normal fissure and cause infection, pain, ulceration, and inflammation. Angular cheilitis is an example of fissures associated with disease. ${ }^{9,12}$

Sinus tract: It is described as a tract extending from a suppurative cavity, cyst, or abscess to the surface of the skin or mucosa (Figure 16). ${ }^{9}$ In the oral cavity, sinus tracts are most often related to abscessed teeth but they may be seen as congenital defects as well., ${ }^{9,12}$

Fistula: It is described as an abnormal pathological pathway between two anatomic spaces or a pathway extending from an internal cavity or organ to the surface of the body (Figure 17). ${ }^{19}$ In the oral cavity, oroantral fistula is a common complication following extraction of maxillary posterior teeth. ${ }^{20}$

Scar: It is defined as a fibrous tissue that replaces the normal tissue resulting from a wound that has healed by resolution rather than regeneration such scars related to oral soft tissue biopsy (Figure 18). ${ }^{21}$ Interestingly, healing of mucosal wounds occurs faster than skin wounds and clinical observations have indicated that mucosal wounds rarely scar. ${ }^{22}$

\section{Discussion}

Primary and secondary lesions can be compared in terms of their size, relationship with the surrounding tissue, and contents, for example vesicle and bulla are classified as primary lesion but they are different in their size. In addition, pustule and vesicle are represented as blister but their contents are different. ${ }^{7,12}$ Except for papule, plaque, vesicle, bulla, petechia, and ecchymosis, other lesions may be seen in any size.

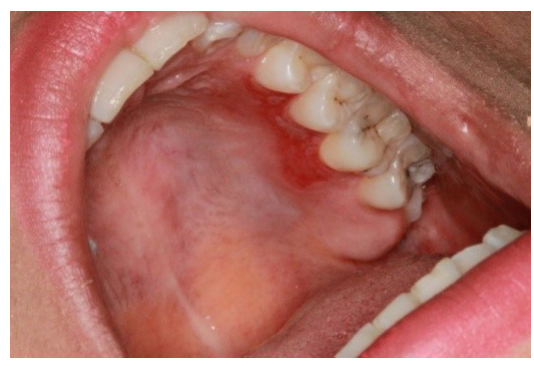

Figure 14. Erosion of the Palatal Mucosa Due to Chemical Trauma.

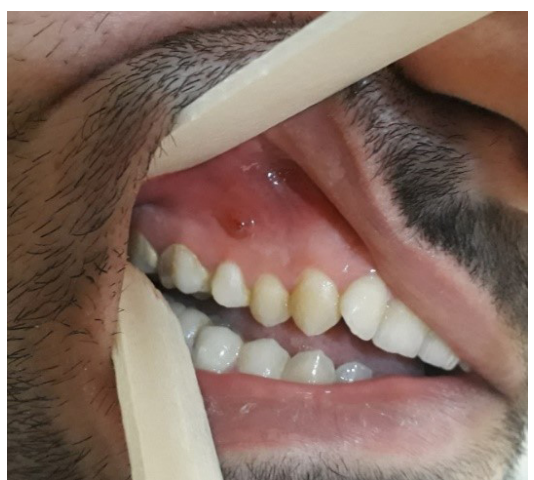

Figure 15. Sinus Tract in Association With a Necrotic Tooth.

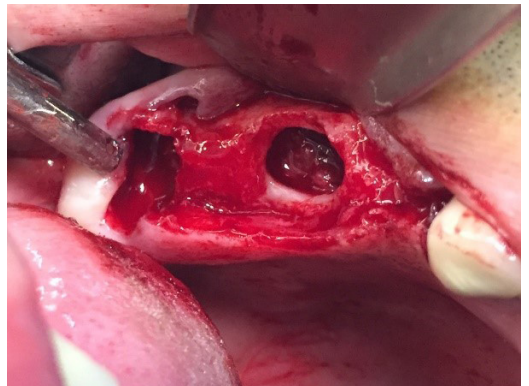

Figure 16. An Oro-antrum Fistula After Dental Extraction.

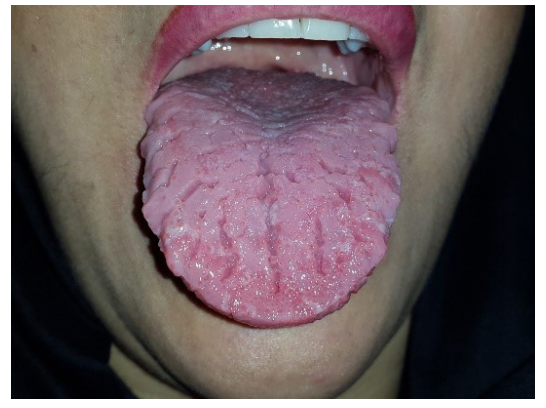

Figure 17. Fissured and Geographic Tongue.

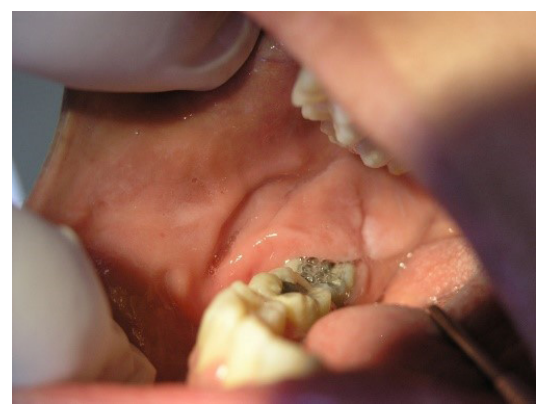

Figure 18. Scar Tissue on the Posterior Portion of the Buccal Mucosa After Surgical Procedure.

However, some researchers have suggested a $5 \mathrm{~mm}$ or $10 \mathrm{~mm}$ cut-off point for papule, plaque, nodule, macule, patch, vesicle and bulla. ${ }^{1,-9}$ An international committee, in its English and German branches, has defined papule to be less than $5 \mathrm{~mm}$ in size. It seems to be the most logical size. However, the French and Spanish branches of international committee, still report $10 \mathrm{~mm}$ as the maximum size. ${ }^{23}$ According to the English and German versions of international committee report, plaque is defined as an elevated area of skin $20 \mathrm{~mm}$ or larger in diameter. Therefore, raised and flat topped lesions, which are between $5 \mathrm{~mm}$ and $20 \mathrm{~mm}$ in size, have no official definition. The result is choosing a small size $(5 \mathrm{~mm})$ for the maximum size of the papule. In contrast, the cut-off point between a papule and a plaque is $10 \mathrm{~mm}$ according to the French and Spanish branches of the international committee. ${ }^{23}$ The maximum size of a nodule is considered to be $5 \mathrm{~mm}$; however; this value is $10 \mathrm{~mm}$ according to the French version of the international committee; whereas, the Spanish version does not mention any size. ${ }^{23}$ The international committee has not provided a size 
limit for macules, although small and large patches have been defined as macules between $5 \mathrm{~mm}$ to $20 \mathrm{~mm}$ and greater than $20 \mathrm{~mm}$, respectively. Therefore, it seems that the maximum size for a macule is $5 \mathrm{~mm} \cdot{ }^{23}$ According to the international committee, the cut-off point between a vesicle and a bulla is $5 \mathrm{~mm} .{ }^{23}$ On the other hand, Marks suggested that, the size of vesicles does not exceed $1 \mathrm{~mm}$ to $2 \mathrm{~mm}$ in diameter. ${ }^{24}$ Jackson also recommended that, the criteria for a vesicle should not be based on its morphology alone. Vesicles develop due to intraepidermal inflammation and a bulla occurs as the result of loss of epidermis cohesiveness or at the junction of epidermis and dermis. ${ }^{25}$ Recently, the 2016 International League of Dermatological Societies published a revised glossary for description of skin lesions and suggested $10 \mathrm{~mm}$ to be the cutoff point between macules and patches, papules and plaques, and vesicles and bullae. ${ }^{26}$ However, these definitions are often influenced by regional and national regulations and therefore, significant variations exist in this respect. ${ }^{26}$

The lesions can be flat, raised or depressed relative to their adjacent skin or mucosa. For example, macules, patches, petechia and ecchymosis are flat lesions; whereas, papules, plaques, nodules, tumors, weal, vesicles, bullae, pustules, abscess, cysts, scars and hematoma are raised lesions. In addition, ulcers, erosions, and fissures are depressed lesions. It is important to know that, lesions such as nodules, cysts and hematomas may be seen in level with the skin or mucosa when they are small or occur deeply. $8,17,26$

In terms of content, the lesions can be divided into two groups of solid and fluid-filled. Papules, plaques, nodules, tumors, weal and scars are considered solid lesions. ${ }^{7,9,26}$ Fluidfilled lesions include vesicles (clear, serous or hemorrhagic), bullae (clear, serous or hemorrhagic), pustules (pus), abscess (pus, blood), cysts (pus, blood, serosanguineous), and hematomas (blood). ${ }^{7,26}$

According to the most recent version of the International League of Dermatological Societies, it is recommended that the mean diameter, shape, color, topography (surface characteristics), border, degree of elevation, consistency or feel should be included in description of a papule, plaque, and nodule. The mean diameter, shape, color, and border should also be considered in description of a macule. On the other hand, in an ulcerative lesion, the size, shape and depth should be described as well as characteristics of the border, base, and the surrounding tissues. ${ }^{26}$

\section{Conclusions}

It can be concluded from this review that, the descriptions reported by authors must be taken into account, and that differences related to the morphological terminology must/ should be accepted. It is up to the teaching institution and/or professionals in the field to use the reference of their choice. In addition, dental students and residents must be well aware of the didactic preference and the reasons behind it. Moreover, institutions must focus their attention to the existence of such possible differences among the many reference textbooks on terminology and semiology, and even among the professionals of the same teaching institution, in an attempt to avoid conflicts and doubts in description of elementary lesions.

\section{Conflict of Interest Disclosures}

The authors declare they have no conflicts of interest.

\section{Acknowledgements}

The authors are greatly thankful to Dr. Somayeh Rahmani, Dr. Soudeh Jafari, Dr. Fahimeh Anbari and Dr. Farzad Aghdashi for their cooperation in preparing images.

\section{References}

1. Glick M. Burkert's oral medicine. PMPH USA; 2015.

2. McCann AL, Wesley RK. A method for describing soft tissue lesions of the oral cavity. Dent Hyg (Chic). 1987;61(5):219-223.

3. Zimmermann C, Meurer MI, Lacerda JT, Mello A, Grando LJ. The use of tools to support oral lesion description in oral medicine referrals. Braz Oral Res. 2017;31:e93. doi:10.1590/18073107BOR-2017.vol31.0093.

4. Navarro CM, Onofre MA, Sposto MR. Referral letters in oral medicine: an approach for the general dental practitioner. Int J Oral Maxillofac Surg. 2001;30(5):448-451. doi:10.1054/ ijom.2001.0108.

5. Subramanyam RV. Oral pathology in clinical dentistry: A systematic approach. J Int Clin Dent Res Organ. 2014;6(2):72-76. doi:10.4103/2231-0754.143476.

6. Mortazavi H, Safi Y, Baharvand M, Rahmani S, Jafari S. Peripheral Exophytic Oral Lesions: A Clinical Decision Tree. Int J Dent. 2017;2017:9193831. doi:10.1155/2017/9193831.

7. Linton CP. Essential morphologic terms and definitions. J Dermatol Nurses Assoc. 2011;3(2):102-103. doi:10.1097/ JDN.0b013e318211c6f0.

8. Ashton RE. Teaching non-dermatologists to examine the skin: a review of the literature and some recommendations. Br J Dermatol. 1995;132(2):221-225. doi:10.1111/j.1365-2133.1995.tb05017.x.

9. Bricker SL, Langlais RP, Miller CS. Oral diagnosis, oral medicine and oral treatment. 2nd ed. Hamilton: BC Decker Inc; 2002. p. 535-593.

10. Nasemann T, Sauerbrey W, Burgdorf WHC. Fundamentals of dermatology. New York: Springer-Verlag; 1983. p. 15-19.

11. Cardili RN, Roselino AM. Elementary lesions in dermatological semiology: literature review. An Bras Dermatol. 2016;91(5):629633. doi:10.1590/abd1806-4841.20164931.

12. Langlais RP, Miller CS, Gehrig JS. Color atlas of common oral diseases. LWW; 2016.

13. Hess CT. SKIN IQ: Primary and Secondary Lesions. Adv Skin Wound Care. 2005;18(1):19.

14. Hill CM, Renton T. Oral surgery II: Part 3. Cysts of the mouth and jaws and their management. Br Dent J. 2017;223(8):573-584. doi:10.1038/sj.bdj.2017.916.

15. Kraus CK, Katz KD. Extensive facial hematoma following third molar removal. Am J Emerg Med. 2014;32(9):1153.e1155-1156. doi:10.1016/j.ajem.2014.02.031.

16. Mortazavi H, Safi Y, Baharvand M, Rahmani S. Diagnostic Features of Common Oral Ulcerative Lesions: An Updated Decision Tree. Int J Dent. 2016;2016:7278925. doi:10.1155/2016/7278925.

17. Muñoz-Corcuera M, Esparza-Gómez G, González-Moles MA, Bascones-Martínez A. Oral ulcers: clinical aspects. A tool for dermatologists. Part I. Acute ulcers. Clin Exp Dermatol. 2009;34(3):289-294. doi:10.1111/j.1365-2230.2009.03220.x.

18. Muñoz-Corcuera M, Esparza-Gómez G, González-Moles MA, Bascones-Martínez A. Oral ulcers: clinical aspects. A tool for dermatologists. Part II. Chronic ulcers. Clin Exp Dermatol. 2009;34(4):456-461. doi:10.1111/j.1365-2230.2009.03219.x.

19. Samir N, Al-Mahrezi A, Al-Sudairy S. Odontogenic Cutaneous Fistula: Report of two cases. Sultan Qaboos Univ Med J. 
2011;11(1):115-118

20. Khandelwal P, Hajira N. Management of Oro-antral Communication and Fistula: Various Surgical Options. World J Plast Surg. 2017;6(1):3-8.

21. Baker R, Urso-Baiarda F, Linge C, Grobbelaar A. Cutaneous scarring: a clinical review. Dermatol Res Pract. 2009;2009:625376. doi:10.1155/2009/625376.

22. Wong JW, Gallant-Behm C, Wiebe C, et al. Wound healing in oral mucosa results in reduced scar formation as compared with skin: evidence from the red Duroc pig model and humans. Wound Repair Regen. 2009;17(5):717-729. doi:10.1111/j.1524475X.2009.00531.x.

23. Winkelmann RK. Glossary of basic dermatology lesions. The
International League of Dermatological Societies Committee on Nomenclature. Acta Derm Venereol Suppl (Stockh). 1987;130:116.

24. Marks R, Dykes P, Motley R. Clinical signs and procedures in dermatology. London: Martin Dunitz; 1993.

25. Jackson R. Definitions in dermatology. A dissertation on some of the terms used to describe the living gross pathology of the human skin. Clin Exp Dermatol. 1978;3(3):241-247. doi:10.1111/j.1365-2230.1978.tb01494.x.

26. Nast A, Griffiths CE, Hay R, Sterry W, Bolognia JL. The 2016 International League of Dermatological Societies' revised glossary for the description of cutaneous lesions. $\mathrm{Br} J$ Dermatol. 2016;174(6):1351-1358. doi:10.1111/bjd.14419. 